\title{
Features of Human Herpesvirus-6A and -6B Entry
}

\author{
Takahiro Maeki, ${ }^{1,2}$ and Yasuko Mori, ${ }^{1,2}$ \\ ${ }^{1}$ Division of Clinical Virology, Kobe University Graduate School of Medicine, Kusunoki-cho, Chuo-ku, Kobe 650-0017, Japan \\ ${ }^{2}$ Laboratory of Virology and Vaccinology, Division of Biomedical Research, National Institute of Biomedical Innovation, \\ 7-6-8 Saito-Asagi, Ibaraki, Osaka 567-0085, Japan
}

Correspondence should be addressed to Yasuko Mori, ymori@nibio.go.jp

Received 1 August 2012; Accepted 25 September 2012

Academic Editor: Anthony V. Nicola

Copyright ( $\odot 2012$ T. Maeki and Y. Mori. This is an open access article distributed under the Creative Commons Attribution License, which permits unrestricted use, distribution, and reproduction in any medium, provided the original work is properly cited.

Human herpesvirus-6 (HHV-6) is a T lymphotropic herpesvirus belonging to the Betaherpesvirinae subfamily. HHV-6 was long classified into variants A and B (HHV-6A and HHV-6B); however, recently, HHV-6A and HHV-6B were reclassified as different species. The process of herpesvirus entry into target cells is complicated, and in the case of HHV-6A and HHV-6B, the detailed mechanism remains to be elucidated, although both viruses are known to enter cells via endocytosis. In this paper, (1) findings about the cellular receptor and its ligand for HHV-6A and HHV-6B are summarized, and (2) a schematic model of HHV-6A's replication cycle, including its entry, is presented. In addition, (3) reports showing the importance of lipids in both the HHV-6A envelope and target-cell membrane for viral entry are reviewed, and (4) glycoproteins involved in cell fusion are discussed.

\section{Introduction}

The herpesviridae are a family of double-stranded enveloped DNA viruses. Their entry into host cells proceeds as follows. First, the virus binds to its target cell through a specific receptor. Second, herpesviruses enter cells via two different pathways: (a) direct fusion of the viral envelope with the target-cell plasma membrane or (b) endocytosis followed by fusion between the viral and cellular membranes in the endosomal compartment [1].

Human herpesvirus-6 (HHV-6) was initially isolated from the peripheral blood of patients with lymphoproliferative disorders, in 1986 [2]. It belongs to the Betaherpesvirinae subfamily, along with human cytomegalovirus (HCMV) and Human herpesvirus-7 (HHV-7), and is a member of the genus Roseolovirus, along with HHV-7. HHV-6 was originally classified into variants $\mathrm{A}$ and $\mathrm{B}$ (HHV-6A and HHV$6 \mathrm{~B})$, based on differences in genetic, antigenic, and growth characteristics [3-5]. However, recently, HHV-6A and HHV6B were reclassified into different species (Virus Taxonomy List 2011). The homology of entire genome sequence between both is nearly 90\% [6-8]. Primary infection of HHV-6B causes exanthem subitum [9], and HHV-6A has been reported to be involved in several diseases, including encephalitis [10], hepatitis [11], glioma [12], and multiple sclerosis [13].

However, the detailed replication cycle of HHV-6A and HHV-6B after entering the cell remains to be elucidated. For some of the steps, different groups have reported conflicting results.

Regarding the ligand and receptor for HHV-6A and HHV-6B, Santoro et al. reported that the cellular receptor for both viruses is CD46 [14]. Our group showed that the glycoprotein $\mathrm{gH} / \mathrm{gL} / \mathrm{gQ} 1 / \mathrm{gQ} 2$ complex [15] is the ligand for HHV-6A [16], and that its receptor is CD46 [17, 18]. However, in the case of HHV-6B (strain HST, an isolate from an infant with exanthem subitum), we reported that, of two complexes found in this virus, $\mathrm{gH} / \mathrm{gL} / \mathrm{gQ}$ and $\mathrm{gH} / \mathrm{gL} / \mathrm{gO}$ neither binds to CD46 [19]. This discrepancy might be due to the difference in HHV-6B strain (Santoro et al. used strains Z29 and PL1, while we used HST) or some other reason.

In this paper, (1) previous reports about the cellular receptor and its ligand for HHV-6A and HHV-6B are summarized, and (2) findings about the entry of HHV-6A and HHV-6B into host cells are reviewed, and a schematic model of HHV-6A's replication cycle is presented. In addition, (3) reports showing the importance of lipids in both the HHV$6 \mathrm{~A}$ envelope and target-cell membrane for viral entry are 
reviewed. Finally, (4) glycoproteins that have been shown to play a critical role in cell fusion (glycoprotein $\mathrm{H}$, glycoprotein B) are discussed briefly.

\section{The Cellular Receptor and Its Ligand for HHV-6A and HHV-6B}

2.1. HHV-6A. As described above, Santoro et al. reported that HHV-6A and HHV-6B use the human complement regulator CD46 as a cellular receptor [14], and our group showed that the $\mathrm{gH} / \mathrm{gL} / \mathrm{gQ} 1 / \mathrm{gQ} 2$ complex of HHV-6A binds to CD46 [17]. Santoro et al. identified gH as the CD46binding component of HHV-6A. They showed that (i) an anti-CD46 antibody immunoprecipitated gH in HHV-6A(GS-strain-) infected cells, (ii) the anti-CD46 antibody did not immunoprecipitate $\mathrm{gH}$ from gH-depleted HHV-6Ainfected cells, although it did immunoprecipitate $\mathrm{gH}$ from gp82-105- or gB-depleted HHV-6A-infected cells, and (iii) a specific anti-gH antibody immunoprecipitated CD46 in HHV-6A-infected cells [20].

Our group showed that not only an anti-gH antibody but also an anti-gQ1 antibody could immunoprecipitate CD46 from HHV-6A- (GS-strain-) infected cells [18]. Furthermore, we recently confirmed that an anti-gQ1 monoclonal antibody (Mab) immunoprecipitates CD46 from HHV-6A(GS-strain-) infected cells (unpublished data) and showed that CD46 immunoprecipitates $\mathrm{gH}, \mathrm{gL}, \mathrm{gQ} 1$, and gQ2 from cells transfected with all four genes [17]. We also showed that the maturation of gQ1, which is indicated by its size shift from $74 \mathrm{kDa}$ (gQ1-74 K) to $80 \mathrm{kDa}$ (gQ1-80 K), occurs only when all four components, gH, gL, gQ1, and gQ2, are coexpressed, and that gQ1-80 K, but not gQ1-74 K, contributes to the $\mathrm{gH} / \mathrm{gL} / \mathrm{gQ} 1 / \mathrm{gQ} 2$ complex and binds to CD46 [17].

CD46 is a member of the glycoprotein family called regulators of complement activation (RCA) [21, 22]. CD46 is a type I transmembrane glycoprotein of 45-67 kDa expressed on all nucleated cells [23]. CD46 contains four short consensus repeats (SCRs) in its N-terminal region, followed by a serine-threonine-proline (STP) rich domain, a small region of unknown significance, a transmembrane domain, and a cytoplasmic tail. Four distinct CD46 isoforms generated by alternative RNA splicing are expressed differentially in various cell types; these isomers have the same SCRs but different STP or cytoplasmic domains [21]. CD46 functions as a cofactor in the factor-I-mediated proteolytic cleavage of $\mathrm{C} 3 \mathrm{~b}$ and $\mathrm{C} 4 \mathrm{~b}$; this process protects host cells from inadvertent lysis by the complement system. CD46's interactions with $\mathrm{C} 3 \mathrm{~b}$ and $\mathrm{C} 4 \mathrm{~b}$ involve several regions on SCR2, SCR3, and SCR4 [24]. CD46 was recently reported to have roles not only in innate immunity but also in adaptive immunity [23]. Furthermore, it was demonstrated that CD46 induces autophagy upon pathogen recognition [25].

CD46 is also used as an entry receptor for several human viruses and bacteria. SCR1 and SCR2 are critical domains for measles virus, SCR3 and the STP region for Neisseria gonorrhoeae, and SCR3 and SCR4 for group A streptococcus [24]. For HHV-6A, our group showed that
SCR2, SCR3, and SCR4 are required for virus-mediated cellcell fusion [26], although other groups reported that SCR2 and SCR3 are the critical determinants for CD46 binding [20] and cell fusion [27]. The reason for the discrepancy is uncertain. It is possible that the direct binding domains are in SCR2 and SCR3, while SCR4 is required only to maintain the conformation of the binding site, because Santoro et al. replaced the SCR4 of CD46 with that of DAF (decay accelerating factor), whereas we deleted SCR4. Further investigation is required to clarify this issue. The structure of extracellular portion of CD46 was recently reported [24], but that of its HHV-6A ligand, the $\mathrm{gH} / \mathrm{gL} / \mathrm{gQ} 1 / \mathrm{gQ} 2$ complex, still needs to be determined.

Of the four components of the HHV-6A gH/gL/gQ1/gQ2 complex, our group reported that gQ1 and gQ2 are essential for viral infection $[17,28]$. We also showed that, in addition to $\mathrm{gH} / \mathrm{gL} / \mathrm{gQ} 1 / \mathrm{gQ} 2$, the HHV-6A viral envelope contains the complex $\mathrm{gH} / \mathrm{gL} / \mathrm{gO}$, which does not bind to human CD46 [19]. The specific molecular function of HHV-6A gO and the $\mathrm{gH} / \mathrm{gL} / \mathrm{gO}$ complex remains to be elucidated. In $\mathrm{HCMV}$, the $\mathrm{gH} / \mathrm{gL} / \mathrm{gO}$ complex is necessary for viral entry into human fibroblasts [29]. In addition, in EBV, the $\mathrm{gH} / \mathrm{gL}$ complex associates with gp42, and this $\mathrm{gH} / \mathrm{gL} / \mathrm{gp} 42$ complex is necessary for viral entry into B cells but not into epithelial cells [30]. CMV also encodes glycoproteins that redirect cell tropism by forming complexes with $\mathrm{gH} / \mathrm{gL}$ [31]. The predicted amino acid identity between the $\mathrm{gO}$ of $\mathrm{HHV}-6 \mathrm{~A}$ and HHV-6B is $76.8 \%$, which is much lower than that of other glycoproteins. Therefore, the $\mathrm{gH} / \mathrm{gL} / \mathrm{gO}$ complex may confer different biological properties in HHV-6A and HHV$6 \mathrm{~B}$, including cell tropism. Efforts to elucidate the function of $\mathrm{gO}$ and $\mathrm{gH} / \mathrm{gL} / \mathrm{gO}$ are underway.

2.2. $H H V-6 B$. In 1999, Santoro et al. reported that CD46 is the receptor for both HHV-6A and HHV-6B [14]. They showed that (i) an anti-CD46 antibody inhibited HHV-6B (strain Z29) infection and HHV-6B-mediated cell fusion in PBMCs and (ii) the expression of CD46 in NIH3T3 cells (mouse fibroblasts) and EL4 cells (murine T lymphoblasts) caused HHV-6B- (strain-PL1-) mediated fusion and entry, respectively. In addition, Pedersen et al. reported that HHV6B (strain PL1) causes fusion from without (FFWO) in HEK293 and SupT-1 cells [32, 33].

However, our group showed that the HHV-6B (strain HST) virion contains $\mathrm{gH} / \mathrm{gL} / \mathrm{gO}$ and $\mathrm{gH} / \mathrm{gL} / \mathrm{gQ}$ complexes, but that neither of them binds to CD46 [19], and that HHV6B (strain HST) does not mediate FFWO in various cell types expressing human CD46, except for MT4 cells [26]. The discrepancy between these results could be attributable to several differences, including the titer of HHV-6B infection, and the $\mathrm{HHV}-6 \mathrm{~B}$ virus strain.

Regarding the glycoprotein complex, it has been found that HHV-6B gH/gL/gQ1/gQ2 complex also plays an important role for the entry [34].

\section{Replication Cycle of HHV-6A and HHV-6B}

3.1. HHV-6A. As shown above, entry of herpesviruses into cells occurs in two distinct steps. In 1992, Cirone 
et al. showed that HHV-6A (strain GS) enters the Tlymphoblastoid cell line, HSB-2 cells, via endocytosis and that no fusion event occurs at the plasma membrane [35]. Since then, no other reports have been shown regarding the HHV-6 entry step. For HHV-6A assembly, the envelopmentdeenvelopment-reenvelopment pathway has been proposed $[36,37]$. In this model, HHV-6A assembly occurs as follows. (i) The intranuclear naked capsid (around $80 \mathrm{~nm}$ in diameter) buds into the perinuclear cisternae, and the nucleocapsid acquires a primary envelope, which is devoid of glycoprotein. (ii) Deenvelopment of the nucleocapsid occurs in the cytoplasm, as shown by the presence of cytoplasmic naked nucleocapsids (around $140 \mathrm{~nm}$ in diameter). (iii) The naked nucleocapsid again acquires an envelope as well as spikes in cytoplasmic vesicles, and, finally, mature viral particles (around $185 \mathrm{~nm}$ in diameter) form. However, many details of this process remain to be elucidated.

Different models have been proposed for tegumentation and for the compartment in which HHV-6A reenvelopment occurs. Regarding tegument acquisition, Roffman et al. reported that $\mathrm{HHV}-6 \mathrm{~B}$ (Z29 strain) virions in infected thymocytes acquire their tegument in tegusomes, which are spherical intranuclear compartments resulting from cytoplasmic invagination into the nucleus, because they contain ribosomes [38]. However, Torrisi et al. could not find such structures in HHV-6A strain GS-infected HSB-2 cells [36]. Later, Ahlqvist et al. suggested that tegumentation of HHV-6A can occur in the nucleus, in the tegusome or in the cytoplasm, or in either of the compartment from the analysis with U1102 infected SupT-1, lymphoblastoid cell line, and HPDA(human progenitor-derived astrocytes) [37]. The different results obtained in these reports could be due to differences in the virus (HHV-6A or HHV-6B), viral strain (HHV-6A GS or U1102), or type of cells used.

As to the reenvelopment compartment, since viral glycoproteins ( $\mathrm{gB}$ and $\mathrm{gH}$ ) are absent from the HHV-6A- (strainGS-) infected HSB-2 cell plasma membrane, the plasma membrane is unlikely to be the site for reenvelopment [39, 40]. Torrisi et al. suggested that reenvelopment at annulate lamellae $(\mathrm{AL})$ is required for HHV-6 to acquire an envelope with spike protein [36]. Cardinali et al. reported that HHV6A- (strain-GS-) infection induced AL in HSB-2 cells, and proposed the $\mathrm{AL}$ as a putative site for oligosaccharide addition, based on the results of labeling with HPL (Helix pomatia lectin, which recognizes intermediate forms of glycoconjugates after the O-linked addition of sugar in cis-Golgi cisternae) and WGA (Wheat germ agglutinin, which binds terminally glycosylated components) [41]. However, Ahlqvist reported that no AL were found in $\mathrm{HHV}-$ 6A- (strain-U1102-) infected astrocytes (HPDA), and that although a low percentage of U1102-infected SupT-1 cells had AL, no viral particles could be found in them. The authors suggested that the spikes of mature viral particles are acquired at cytoplasmic vesicles of unknown origin [37].

Recently, our group showed that HHV-6A (strain GS) induces MVB (multivesicular body) formation, that the final envelopment of HHV-6A occurs at trans-Golgi network (TGN-) or post-TGN-derived membranes, and that enveloped virions are released by the exosomal pathway [42].
We found AL structures in HHV-6A-infected cells and some virions inside AL structures. However, the membranes that surrounded or enwrapped the HHV-6A virions were not derived from $\mathrm{AL}$, because the enveloped capsids in the AL were found inside vacuoles that were further enwrapped by AL membrane. Furthermore, immunostaining with anti-gB and anti-gM antibodies showed that $\mathrm{gB}$ and gM were abundant on the nucleocapsid-enwrapping membranes, while they were scarce on the AL, suggesting that the origins of the two membranes were different. Regarding tegumentation, we found tegument-like electron-dense material on the cytosolic side of TGN-derived vacuoles and at other regions on these vacuoles.

A model for the replication cycle of HHV-6A based on published reports is as follows [43] (Figure 1). The HHV-6A ligand, the $\mathrm{gH} / \mathrm{gL} / \mathrm{gQ} 1 / \mathrm{gQ} 2$ complex, binds to its receptor CD46 (1), the other viral glycoprotein(s) (e.g., gB) also binds to unidentified cellular receptor(s) and enters the cell via endocytosis (2). After deenvelopment by fusion between the viral and cellular membranes in the endosomal compartment (3), the incoming nucleocapsid is transported through the cytoplasm to the nuclear pore complex (4), where the viral DNA genome is unpackaged and released into the nucleus (5). In the nucleus, viral gene transcription and genome replication occur (6). Long concatemeric strands of progeny DNA are cleaved to unit lengths and encapsidated (7). The capsids bud into the perinuclear cisternae (8) and acquire a primary envelope in the perinuclear space (9). Deenvelopment of the nucleocapsid occurs in the cytoplasm (10), and reenvelopment occurs by budding into TGNor post-TGN-derived membranes (11). Finally, the virioncontaining vacuoles expand and MVBs are formed (12), and the enveloped virions are released by the exosomal pathway by fusion of the MVBs with the plasma membrane (13).

3.2. HHV-6B. Compared with HHV-6A, fewer reports have been published on the details of $\mathrm{HHV}-6 \mathrm{~B}$ replication. In 1990, Nii et al. proposed the envelopment-deenvelopmentreenvelopment pathway model for HHV-6B (Hashimoto), based on examinations of infected MT4 cells and human lymphocytes [44]. Ahlqvist et al. supported this model with observations in Z29-infected SupT-1 cells [37].

Conflicting results had been reported about HHV-6B's tegumentation, as with $\mathrm{HHV}-6 \mathrm{~A}$. Nii et al. found that tegument-coated capsids could be detected only in the cytoplasm, and not in the nucleus or perinuclear cisternae, suggesting that tegumentation occurred in the cytoplasm [44]. However, as described above, Roffman et al. reported that HHV-6B (Z29 stain) acquires its tegument at the tegument compartment [38], and Ahlqvist et al. supported this model by showing that Z29-infected SupT-1 cells form tegusomes [37]. Regarding AL, Ahlqvist et al. reported that no AL could be found in the Z29-infected SupT-1 cells [37].

\section{Lipid in the HHV-6A Envelope and Target-Cell Membrane}

Our group showed that cholesterol in both the HHV-6A envelope and target cell is required for HHV-6A entry [45, 


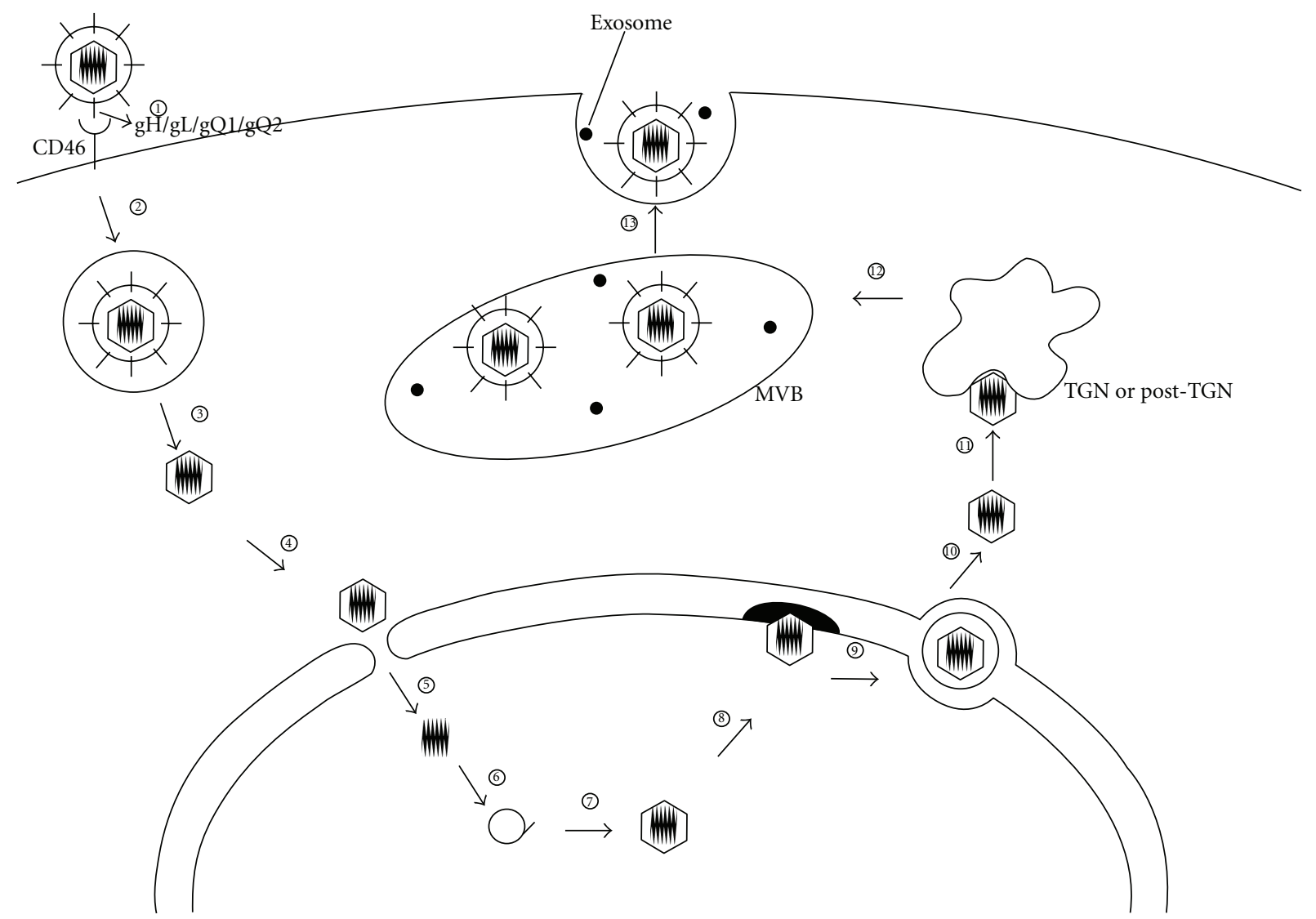

FIgURE 1: Schematic representation of the HHV-6A replication cycle. A diagram of the proposed replication cycle for HHV-6A is shown. HHV-6A gH/gL/gQ1/gQ2 binds to CD46 (1) and enters the cell via endocytosis (2). The deenveloped nucleocapsid is then transported to the nucleus $(3,4)$, where the viral genome is released (5). After viral gene transcription and genome replication (6), the progeny DNA is encapsidated (7), and the capsid buds into the perinuclear cisternae (8). The capsid acquires a primary envelope in the perinuclear space (9), and deenvelopment occurs in the cytoplasm (10). The nucleocapsid acquires the final envelope by budding into TGN- or post-TGN-derived membrane (11). Vacuoles containing virions expand and form MVBs (12), then the mature enveloped virions are released via the exosomal pathway (13).

46]. In addition, we showed that HHV-6A infection induces the relocation of CD46 into lipid rafts and that glycoproteins $(\mathrm{gQ1}$ and $\mathrm{gB})$ are associated with lipid rafts, indicating that lipid rafts of the cell membrane are important for viral entry and that HHV-6A may enter the target cells via lipid rafts [46]. Furthermore, we reported that the HHV-6A envelope contains lipid rafts, suggesting that HHV-6A virions might assemble through lipid rafts [47]. These results show that lipid rafts in both the HHV-6A envelope and its target cells play a critical role in HHV-6A entry and might be involved in HHV-6A virus assembly.

\section{Glycoproteins That May Be Involved in Cell Fusion}

Glycoprotein B (gB), glycoprotein H (gH), and glycoprotein $\mathrm{L}(\mathrm{gL})$, are conserved in all herpesviruses, and essential for entry [48]. As in other herpesviruses, $\mathrm{gB}$ and $\mathrm{gH}$ in HHV-6A and HHV-6B are known targets for neutralizing antibodies, so they are known to be major determinants for cell entry in HHV-6A and HHV-6B $[49,50]$. Futhermore, we showed that
$\mathrm{gB}$ and $\mathrm{gH}$ are required for U1102-induced polykaryocyte formation [26].

For other herpesviruses, especially HSV, reports have accumulated about the roles of viral glycoproteins in entry $[1,29,30,51-53]$, and structural analyses of herpesvirus glycoproteins have been performed [54-56]. EBV utilizes gp42 with gH/gL as a switch of cell tropism and the structural analysis of gp42 has also been done $[1,57]$.

However, in the case of HHV-6A and HHV-6B, the structures of the $\mathrm{gH} / \mathrm{gL}$ or $\mathrm{gH} / \mathrm{gL} / \mathrm{gQ} 1 / \mathrm{gQ} 2$ complexes have not yet been reported, and the detailed mechanisms remain unknown. To unveil the entry mechanisms in detail, determination of the $\mathrm{gH} / \mathrm{gL}$ and $\mathrm{gH} / \mathrm{gL} / \mathrm{gQ} 1 / \mathrm{gQ} 2$ structures and detailed analyses of each glycoprotein's function are needed.

\section{References}

[1] S. A. Connolly, J. O. Jackson, T. S. Jardetzky, and R. Longnecker, "Fusing structure and function: a structural view of the herpesvirus entry machinery," Nature Reviews Microbiology, vol. 9, no. 5, pp. 369-381, 2011. 
[2] S. Z. Salahuddin, D. V. Ablashi, and P. D. Markham, "Isolation of a new virus, HBLV, in patients with lymphoproliferative disorders," Science, vol. 234, no. 4776, pp. 596-601, 1986.

[3] D. V. Ablashi, N. Balachandran, S. F. Josephs et al., "Genomic polymorphism, growth properties, and immunologic variations in human herpesvirus-6 isolates," Virology, vol. 184, no. 2, pp. 545-552, 1991.

[4] J. T. Aubin, H. Collandre, D. Candotti et al., "Several groups among human herpesvirus 6 strains can be distinguished by Southern blotting and polymerase chain reaction," Journal of Clinical Microbiology, vol. 29, no. 2, pp. 367-372, 1991.

[5] B. Chandran, S. Tirawatnapong, B. Pfeiffer, and D. V. Ablashi, "Antigenic relationships among human herpesvirus-6 isolates," Journal of Medical Virology, vol. 37, no. 4, pp. 247-254, 1992.

[6] Y. Isegawa, T. Mukai, K. Nakano et al., "Comparison of the complete DNA sequences of human herpesvirus 6 variants A and B," Journal of Virology, vol. 73, no. 10, pp. 8053-8063, 1999.

[7] U. A. Gompels, J. Nicholas, G. Lawrence et al., "The DNA sequence of human herpesvirus-6: structure, coding content, and genome evolution," Virology, vol. 209, no. 1, pp. 29-51, 1995.

[8] G. Dominguez, T. R. Dambaugh, F. R. Stamey, S. Dewhurst, N. Inoue, and P. E. Pellett, "Human herpesvirus 6B genome sequence: coding content and comparison with human herpesvirus 6A," Journal of Virology, vol. 73, no. 10, pp. 80408052, 1999.

[9] K. Yamanishi, T. Okuno, K. Shiraki et al., "Identification of human herpesvirus- 6 as a causal agent for exanthem subitum," Lancet, vol. 1, no. 8594, pp. 1065-1067, 1988.

[10] M. Portolani, M. Pecorari, M. G. Tamassia, W. Gennari, F. Beretti, and G. Guaraldi, "Case of fatal encephalitis by HHV-6 variant A," Journal of Medical Virology, vol. 65, no. 1, pp. 133137, 2001.

[11] L. Potenza, M. Luppi, P. Barozzi et al., "HHV-6A in syncytial giant-cell hepatitis," New England Journal of Medicine, vol. 359, no. 6, pp. 593-602, 2008.

[12] J. Chi, B. Gu, and C. Zhang, "Human herpesvirus 6 latent infection in patients with glioma," Journal of Infectious Diseases, vol. 206, no. 9, pp. 1394-1398, 2012.

[13] N. Akhyani, R. Berti, M. B. Brennan et al., "Tissue distribution and variant characterization of human herpesvirus (HHV)6: increased prevalence of HHV-6A in patients with multiple sclerosis," Journal of Infectious Diseases, vol. 182, no. 5, pp. 1321-1325, 2000.

[14] F. Santoro, P. E. Kennedy, G. Locatelli, M. S. Malnati, E. A. Berger, and P. Lusso, "CD46 is a cellular receptor for human herpesvirus 6," Cell, vol. 99, no. 7, pp. 817-827, 1999.

[15] P. Akkapaiboon, Y. Mori, T. Sadaoka, S. Yonemoto, and K. Yamanishi, "Intracellular processing of human herpesvirus 6 glycoproteins Q1 and Q2 into tetrameric complexes expressed on the viral envelope," Journal of Virology, vol. 78, no. 15, pp. 7969-7983, 2004.

[16] Y. Mori, "Recent topics related to human herpesvirus 6 cell tropism," Cellular Microbiology, vol. 11, no. 7, pp. 1001-1006, 2009.

[17] H. Tang, M. Hayashi, T. Maeki, K. Yamanishi, and Y. Mori, "Human herpesvirus 6 glycoprotein complex formation is required for folding and trafficking of the $\mathrm{gH} / \mathrm{gL} / \mathrm{gQ} 1 / \mathrm{gQ} 2$ complex and its cellular receptor binding," Journal of Virology, vol. 85, no. 21, pp. 11121-11130, 2011.
[18] Y. Mori, X. Yang, P. Akkapaiboon, T. Okuno, and K. Yamanishi, "Human herpesvirus 6 variant A glycoprotein Hglycoprotein L-glycoprotein Q complex associates with human CD46," Journal of Virology, vol. 77, no. 8, pp. 4992-4999, 2003.

[19] Y. Mori, P. Akkapaiboon, S. Yonemoto et al., "Discovery of a second form of tripartite complex containing gH-gL of human herpesvirus 6 and observations on CD46," Journal of Virology, vol. 78, no. 9, pp. 4609-4616, 2004.

[20] F. Santoro, H. L. Greenstone, A. Insinga et al., "Interaction of glycoprotein $\mathrm{H}$ of human herpesvirus 6 with the cellular receptor CD46," Journal of Biological Chemistry, vol. 278, no. 28, pp. 25964-25969, 2003.

[21] T. Seya, A. Hirano, M. Matsumoto, M. Nomura, and S. Ueda, "Human membrane cofactor protein (MCP, CD46): multiple isoforms and functions," International Journal of Biochemistry and Cell Biology, vol. 31, no. 11, pp. 1255-1260, 1999.

[22] S. Thulke, A. Radonić, A. Nitsche, and W. Siegert, "Quantitative expression analysis of HHV-6 cell receptor CD46 on cells of human cord blood, peripheral blood and G-CSF mobilised leukapheresis cells," Virology Journal, vol. 3, article 77, 2006.

[23] J. Cardone, G. Le Friec, and C. Kemper, "CD46 in innate and adaptive immunity: an update," Clinical and Experimental Immunology, vol. 164, no. 3, pp. 301-311, 2011.

[24] B. D. Persson, N. B. Schmitz, C. Santiago et al., "Structure of the extracellular portion of CD46 provides insights into its interactions with complement proteins and pathogens," PLoS Pathogens, vol. 6, no. 9, Article ID e01122, 2010.

[25] P. E. Joubert, G. Meiffren, I. P. Grégoire et al., "Autophagy induction by the pathogen receptor CD46," Cell Host and Microbe, vol. 6, no. 4, pp. 354-366, 2009.

[26] Y. Mori, T. Seya, H. L. Huang, P. Akkapaiboon, P. Dhepakson, and K. Yamanishi, "Human herpesvirus 6 variant A but not variant B induces fusion from without in a variety of human cells through a human herpesvirus 6 entry receptor, CD46," Journal of Virology, vol. 76, no. 13, pp. 6750-6761, 2002.

[27] H. L. Greenstone, F. Santoro, P. Lusso, and E. A. Berger, "Human herpesvirus 6 and measles virus employ distinct CD46 domains for receptor function," Journal of Biological Chemistry, vol. 277, no. 42, pp. 39112-39118, 2002.

[28] H. Tang, A. Kawabata, M. Yoshida et al., "Human herpesvirus 6 encoded glycoprotein Q1 gene is essential for virus growth," Virology, vol. 407, no. 2, pp. 360-367, 2010.

[29] M. G. Revello and G. Gerna, "Human cytomegalovirus tropism for endothelial/epithelial cells: scientific background and clinical implications," Reviews in Medical Virology, vol. 20, no. 3, pp. 136-155, 2010.

[30] L. M. Hutt-Fletcher, "Epstein-Barr virus entry," Journal of Virology, vol. 81, no. 15, pp. 7825-7832, 2007.

[31] D. Wang and T. Shenk, "Human cytomegalovirus virion protein complex required for epithelial and endothelial cell tropism," Proceedings of the National Academy of Sciences of the United States of America, vol. 102, no. 50, pp. 18153-18158, 2005.

[32] S. M. Pedersen, B. Øster, B. Bundgaard, and P. Höllsberg, "Induction of cell-cell fusion from without by human herpesvirus 6B," Journal of Virology, vol. 80, no. 19, pp. 99169920, 2006.

[33] S. M. Pedersen and P. Höllsberg, "Complexities in human herpesvirus-6A and -6B binding to host cells," Virology, vol. 356, no. 1-2, pp. 1-3, 2006.

[34] A. Kawabata, H. Oyaizu, T. Maeki, H. Tang, K. Yamanishi, and Y. Mori, "Analysis of a neutralizing antibody for human 
herpesvirus 6B reveals a role for glycoprotein Q1 in viral entry," Journal of Virology, vol. 85, no. 24, pp. 12962-12971, 2011.

[35] M. Cirone, C. Zompetta, A. Angeloni et al., "Infection by human herpesvirus 6 (HHV-6) of human lymphoid T cells occurs through an endocytic pathway," AIDS Research and Human Retroviruses, vol. 8, no. 12, pp. 2031-2037, 1992.

[36] M. R. Torrisi, M. Gentile, G. Cardinali et al., "Intracellular transport and maturation pathway of human herpesvirus 6," Virology, vol. 257, no. 2, pp. 460-471, 1999.

[37] J. Ahlqvist, D. Donati, E. Martinelli et al., "Complete replication cycle and acquisition of tegument in nucleus of human herpesvirus 6A in astrocytes and in T-cells," Journal of Medical Virology, vol. 78, no. 12, pp. 1542-1553, 2006.

[38] E. Roffman, J. P. Albert, J. P. Goff, and N. Frenkel, "Putative site for the acquisition of human herpesvirus 6 virion tegument," Journal of Virology, vol. 64, no. 12, pp. 6308-6313, 1990.

[39] M. Cirone, G. Campadelli-Fiume, L. Foa-Tomasi, M. R. Torrisi, and A. Faggioni, "Human herpesvirus 6 envelope glycoproteins B and H-L complex are undetectable on the plasma membrane of infected lymphocytes," AIDS Research and Human Retroviruses, vol. 10, no. 2, pp. 175-179, 1994.

[40] P. Biberfeld, B. Kramarsky, S. Z. Salahuddin, and R. C. Gallo, "Ultrastructural characterization of a new human B lymphotropic DNA virus (human herpesvirus 6) isolated from patients with lymphoproliferative disease," Journal of the National Cancer Institute, vol. 79, no. 5, pp. 933-941, 1987.

[41] G. Cardinali, M. Gentile, M. Cirone et al., "Viral glycoproteins accumulate in newly formed annulate lamellae following infection of lymphoid cells by human herpesvirus 6," Journal of Virology, vol. 72, no. 12, pp. 9738-9746, 1998.

[42] Y. Mori, M. Koike, E. Moriishi et al., "Human herpesvirus6 induces MVB formation, and virus egress occurs by an exosomal release pathway," Traffic, vol. 9, no. 10, pp. 17281742, 2008.

[43] L. De Bolle, L. Naesens, and E. De Clercq, "Update on human herpesvirus 6 biology, clinical features, and therapy," Clinical Microbiology Reviews, vol. 18, no. 1, pp. 217-245, 2005.

[44] S. Nii, M. Yoshida, F. Uno, T. Kurata, K. Ikuta, and K. Yamanishi, "Replication of human herpesvirus 6 (HHV-6): morphological aspects," Advances in Experimental Medicine and Biology, vol. 278, pp. 19-28, 1990.

[45] H. Huang, Y. Li, T. Sadaoka et al., "Human herpesvirus 6 envelope cholesterol is required for virus entry," Journal of General Virology, vol. 87, no. 2, pp. 277-285, 2006.

[46] H. Tang, A. Kawabata, M. Takemoto, K. Yamanishi, and Y. Mori, "Human herpesvirus-6 infection induces the reorganization of membrane microdomains in target cells, which are required for virus entry," Virology, vol. 378, no. 2, pp. 265-271, 2008.

[47] A. Kawabata, H. Tang, H. Huang, K. Yamanishi, and Y. Mori, "Y Human herpesvirus 6 envelope components enriched in lipid rafts: evidence for virion-associated lipid rafts," Virology Journal, vol. 6, article 127, 2009.

[48] P. G. Spear and R. Longnecker, "Herpesvirus entry: an update," Journal of Virology, vol. 77, no. 19, pp. 10179-10185, 2003.

[49] K. Takeda, T. Okuno, Y. Isegawa, and K. Yamanishi, "Identification of a variant A-specific neutralizing epitope on glycoprotein B (gB) of human herpesvirus-6 (HHV-6)," Virology, vol. 222, no. 1, pp. 176-183, 1996.

[50] K. Takeda, M. Haque, T. Sunagawa, T. Okuno, Y. Isegawa, and K. Yamanishi, "Identification of a variant B-specific neutralizing epitope on glycoprotein $\mathrm{H}$ of human herpesvirus6," Journal of General Virology, vol. 78, no. 9, pp. 2171-2178, 1997.

[51] R. J. Eisenberg, D. Atanasiu, T. M. Cairns, J. R. Gallagher, C. Krummenacher, and G. H. Cohen, "Herpes virus fusion and entry: a story with many characters," Viruses, no. 5, pp. 800832, 20124.

[52] D. Atanasiu, W. T. Saw, G. H. Cohen, and R. J. Eisenberg, "Cascade of events governing cell-cell fusion induced by herpes simplex virus glycoproteins gD, gH/gL, and gB," Journal of Virology, vol. 84, no. 23, pp. 12292-12299, 2010.

[53] G. Campadelli-Fiume, M. Amasio, E. Avitabile et al., "The multipartite system that mediates entry of herpes simplex virus into the cell," Reviews in Medical Virology, vol. 17, no. 5, pp. 313-326, 2007.

[54] T. K. Chowdary, T. M. Cairns, D. Atanasiu, G. H. Cohen, R. J. Eisenberg, and E. E. Heldwein, "Crystal structure of the conserved herpesvirus fusion regulator complex gH-gL," Nature Structural and Molecular Biology, vol. 17, no. 7, pp. 882-888, 2010.

[55] E. E. Heldwein, H. Lou, F. C. Bender, G. H. Cohen, R. J. Eisenberg, and S. C. Harrison, "Crystal structure of glycoprotein B from herpes simplex virus 1," Science, vol. 313, no. 5784, pp. 217-220, 2006.

[56] H. Matsuura, A. N. Kirschner, R. Longnecker, and T. S. Jardetzky, "Crystal structure of the Epstein-Barr virus (EBV) glycoprotein H/glycoprotein L (gH/gL) complex," Proceedings of the National Academy of Sciences of the United States of America, vol. 107, no. 52, pp. 22641-22646, 2010.

[57] C. M. Borza and L. M. Hutt-Fletcher, "Alternate replication in B cells and epithelial cells switches tropism of Epstein-Barr virus," Nature Medicine, vol. 8, no. 6, pp. 594-599, 2002. 

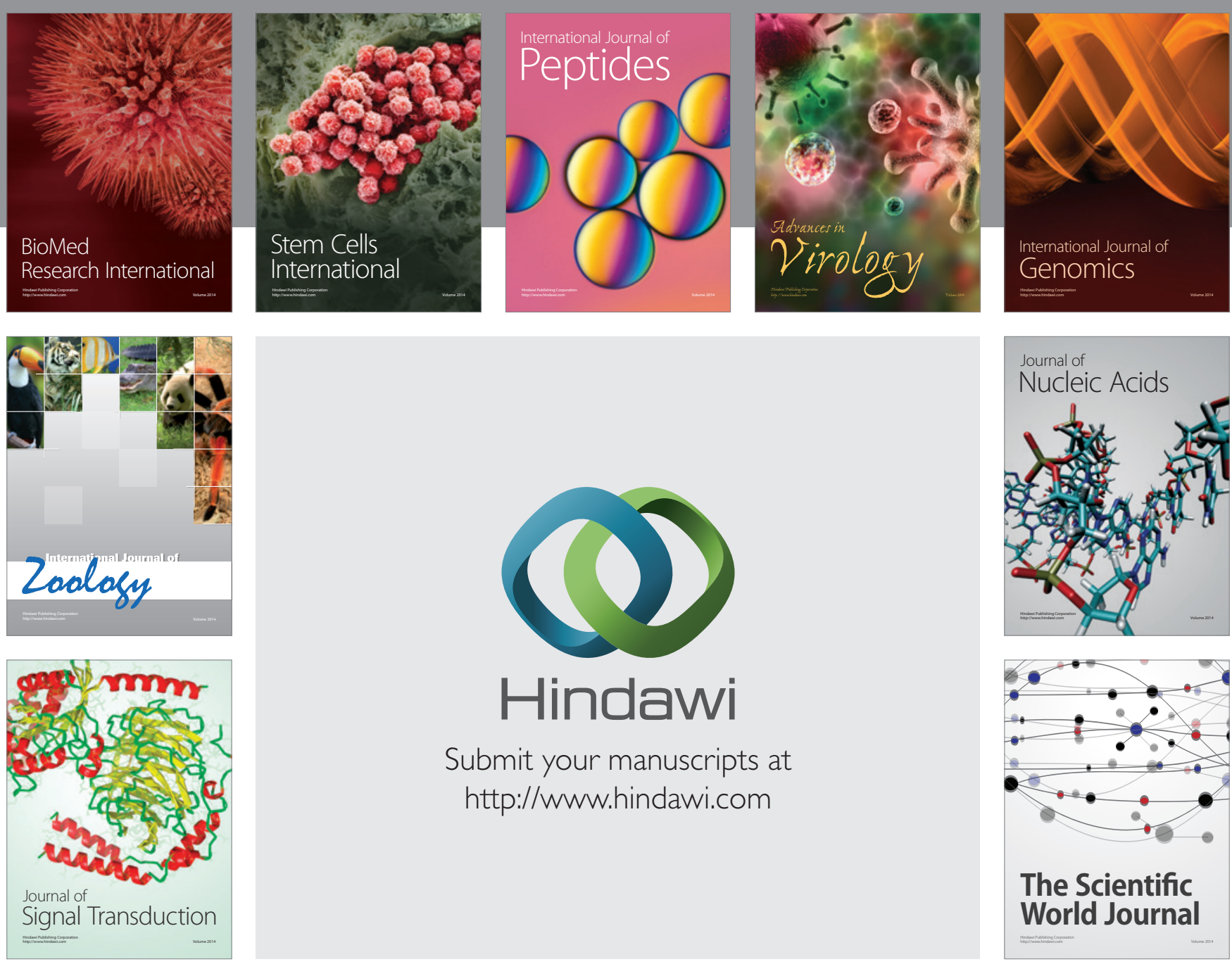

Submit your manuscripts at

http://www.hindawi.com
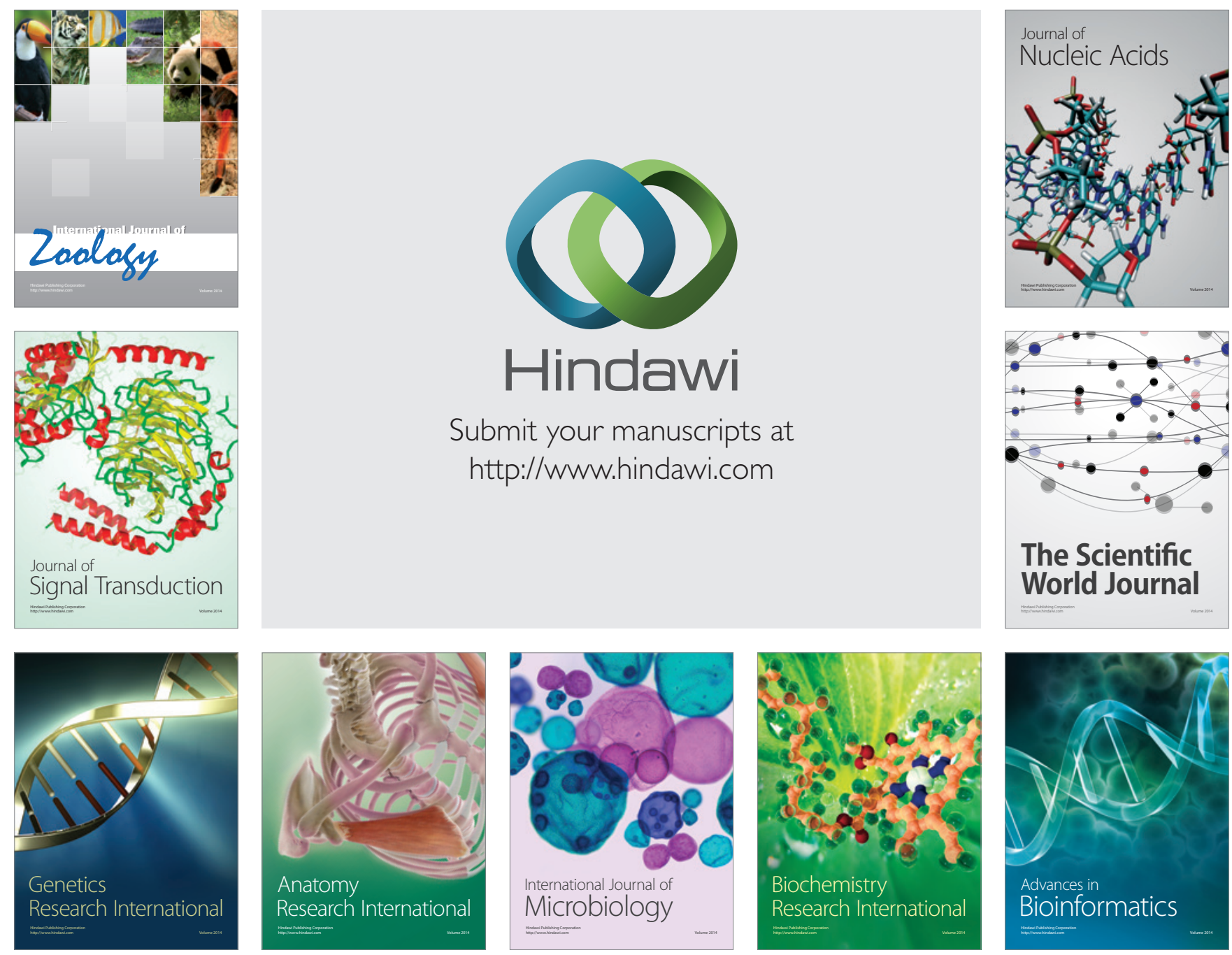

The Scientific World Journal
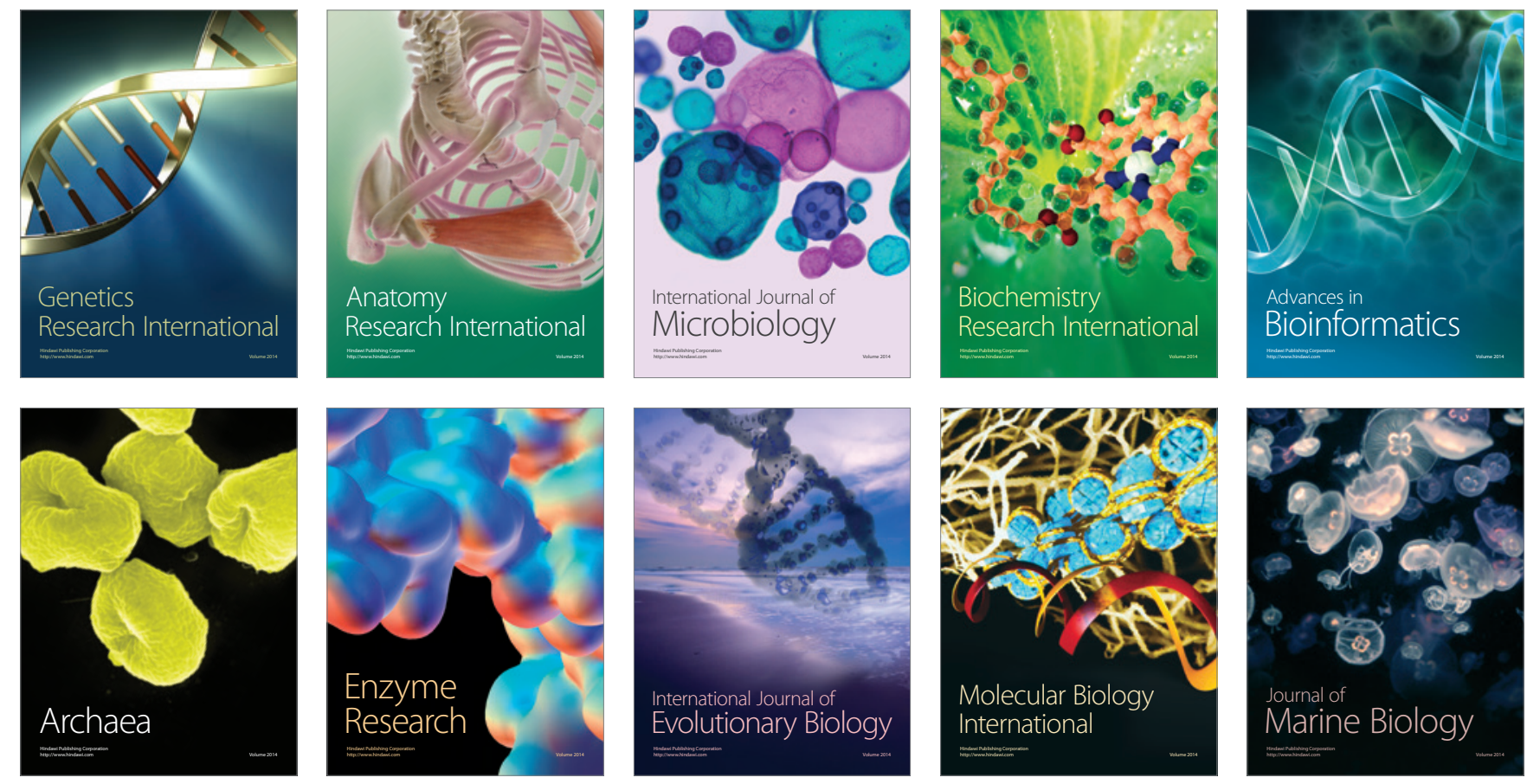